\title{
Tongue Growth during Prenatal Development in Korean Fetuses and Embryos
}

\author{
Soo Jeong Hong · Bong Geun $\mathrm{Cha}^{1}$ \\ Yeon Sook $\mathrm{Kim}^{2}$ · Suk Keun Lee \\ Je Geun $\mathrm{Chi}^{3}$ \\ Departments of Oral Pathology and \\ ${ }^{1}$ Orthodontics, College of Dentistry, \\ Gangnueng-Wonju National University, \\ Gangneung; 'Department of Dental Hygiene, \\ College of Health Sciences, Cheongju University, \\ Cheongju; ' ${ }^{3}$ Department of Pathology, Seoul \\ National University College of Medicine, Seoul, \\ Korea \\ Received: September 13, 2015 \\ Accepted: September 17, 2015 \\ Corresponding Author \\ Suk Keun Lee, DDS \\ Department of Oral Pathology, College of Dentistry, \\ Gangnueng-Wonju National University, \\ 7, Jukheon-gil, Gangneung 25457, Korea \\ Tel: +82-33-640-2228 \\ Fax: +82-33-642-6410 \\ E-mail: sukkeunlee@hanmail.net
}

\begin{abstract}
Background: Prenatal tongue development may affect oral-craniofacial structures, but this muscular organ has rarely been investigated. Methods: In order to document the physiology of prenatal tongue growth, we histologically examined the facial and cranial base structures of 56 embryos and 106 fetuses. Results: In Streeter's stages 13-14 (fertilization age [FA], 28 to 32 days), the tongue protruded into the stomodeal cavity from the retrohyoid space to the cartilaginous mesenchyme of the primitive cranial base, and in Streeter's stage 15 (FA, 33 to 36 days), the tongue rapidly swelled and compressed the cranial base to initiate spheno-occipital synchondrosis and continued to swell laterally to occupy most of the stomodeal cavity in Streeter's stage 16-17 (FA, 37 to 43 days). In Streeter's stage 18-20 (FA, 44 to 51 days), the tongue was vertically positioned and filled the posterior nasopharyngeal space. As the growth of the mandible and maxilla advanced, the tongue was pulled down and protruded anteriorly to form the linguomandibular complex. Angulation between the anterior cranial base (ACB) and the posterior cranial base (PCB) was formed by the emerging tongue at FA 4 weeks and became constant at approximately $124^{\circ}-$ $126^{\circ}$ from FA 6 weeks until birth, which was consistent with angulations measured on adult cephalograms. Conclusions: The early clockwise growth of the ACB to the maxillary plane became harmonious with the counter-clockwise growth of the PCB to the tongue axis during the early prenatal period. These observations suggest that human embryonic tongue growth affects ACB and PCB angulation, stimulates maxillary growth, and induces mandibular movement to achieve the essential functions of oral and maxillofacial structures.
\end{abstract}

Key Words: Tongue; Development; Human embryos and fetuses
Embryonically, tongue development is described as a relatively prompt process: the tongue primordium emerges between fertilization age (FA) 4 and 5 weeks. Unlike maxillary and mandibular structures, the tongue primordium differentiates from the occipital myotome, and the primitive cell cluster of tongue primordium then migrates into the stomodeal cavity. ${ }^{1-8}$ It has been well documented that tongue development has a notable effect on oral cavity development, ${ }^{2,9-13}$ and thus, tongue development should be monitored from the early embryonic stage, during which orofacial structures are not fully developed. However, the overall processes of tongue development cannot be monitored using conventional methods, because the tongue is not a uniform organ with a skeletal framework and its development is closely associated with the formation of branchial arches during the early embryonic stage. ${ }^{11,14-17}$ Nevertheless, a recent trial demonstrated the gene profile of developing tongues in mouse embryos. ${ }^{18}$

The book Contribution to Embryology published by the Carnegie Institute has played a pivotal role in the advancement of human embryology. ${ }^{719-21}$ However, somewhat surprisingly, the determination of exact gestational age during early embryogenesis remains a controversial issue. Based on cumulated experience, Streeter ${ }^{19,20}$ introduced the concept of "developmental horizons" to describe the embryonic stage at different gestational ages. Later, O'Rahilly ${ }^{21}$ proposed that Streeter's "developmental horizons" be modified for convenience, and that "horizon" and the use of Roman numerals be replaced by "stage" and Arabic numerals, respectively. In the present study, we use Streeter's original classification method as modified by O'Rahilly.

The tongue is innervated by various nerves that subserve muscles, oral mucosa, taste buds, and minor salivary glands. These nerves include the lingual branch of the trigeminal nerve $(\mathrm{V})$, the glossopharyngeal nerve (IX), the chorda tympani branch of the facial nerve (VII), and the hypoglossal nerve (XII), which are distributed to motor components of innervated muscles. ${ }^{17,22,23}$ In a previous study, we described the sequential prenatal development of the human maxilla, cranial base, and mandible. ${ }^{24-26}$ In addition, we published a book titled Atlas of Human Embryo and 
Fetus: Embryonic, Anatomic, Histologic and Ultrasonographic Observation that describes human embryonic and fetal growth from the early embryonic period to full term based on studies performed on more than 2,500 Korean subjects. ${ }^{27}$

Given the background described above, this study was undertaken to determine whether tongue development is closely related to the development of maxillofacial structures. To achieve this, we performed histological analyses on tongues and adjacent tissues from the early to the late embryonic stage. The preliminary study of human tongue development and growth was reported in $1990,{ }^{28}$ and this study reevaluated previous data for anatomical and dimensional changes of oral and craniofacial structures. Prenatal tongue growth was investigated by measuring the anterior cranial base (ACB) to posterior cranial base (PCB) angle (the so-called saddle angle), the ACB to maxillary plane angle, the tongue axis to $\mathrm{PCB}$ angle, and the tongue axis to maxillary plane angle. In addition, these angular measurements were compared with adult values obtained from cephalometric X-ray views. ${ }^{29}$

\section{MATERIALS AND METHODS}

For the embryo study, serial sections were prepared from 56 embryos between FA 4 and 8 weeks filed in the Embryonal Serial Section Registry (ESR). For the fetus study, 106 normal Korean fetuses filed in the Registry of Congenital Malformation (RCM) and Children's Hospital for Autopsy (CHA) registry of Seoul National University Hospital (SNUH) were used. These fetuses were confirmed to be normal by complete autopsy, and their ages ranged between gestational age 10 and 41 weeks (Tables 1, 2). Human embryos and fetuses were used after obtaining consent from the Human Organ and Material Committee of SNUH. ${ }^{27}$

Specimens were fixed in $10 \%$ neutral formalin and then paraffin-embedded. Sagittal serial sections of a thickness 4 to $6 \mu \mathrm{m}$ were prepared. When making these sections, head-and-neck size was considered; in smaller cases, the head and neck were serially sectioned, including the tongue, but in larger cases, the tongue was totally extracted from the oral cavity with surrounding structures and sectioned longitudinally at 4 to $6 \mu \mathrm{m}$. For light microscopy, specimens were stained with hematoxylin and eosin.

For the analysis of normal adult cephalograms, we selected 30 representative cephalograms of normal subjects that visited Han Bit Clinic in Daejeon city for orthodontic counseling or treatment. All subjects had a normal craniofacial profile and showed no anterior-posterior craniofacial skeletal disharmony. In order to elucidate the developmental role of the tongue, we
Table 1. Human embryos used in this study

\begin{tabular}{|c|c|c|}
\hline $\begin{array}{l}\text { Embryonal } \\
\text { age (day) }\end{array}$ & $\begin{array}{l}\text { Streeter's } \\
\text { stage }\end{array}$ & No. of ESR or RCM \\
\hline $28-30$ & 13 & 5 (E49, E77, E83, E95, E176) \\
\hline $31-32$ & 14 & 4 (E9, E27, E89, E94) \\
\hline $33-36$ & 15 & 8 (E5, E45, E48, E82, E93, E113, E142, E180) \\
\hline $37-40$ & 16 & $4(\mathrm{E} 59, \mathrm{E} 61, \mathrm{E} 68, \mathrm{E} 183)$ \\
\hline $41-43$ & 17 & 9 (E1, E8, E26, E30, E35, E37, E63, E72, E108) \\
\hline $44-46$ & 18 & 3 (E12, E24, E168) \\
\hline $47-48$ & 19 & 2 (E13, E48) \\
\hline $49-51$ & 20 & 6 (E4, E18, E28, E31, E43, E92) \\
\hline $52-53$ & 21 & $3(\mathrm{E} 17, \mathrm{E} 67, \mathrm{E} 70)$ \\
\hline $54-55$ & 22 & 4 (E25, E85, E96, R448) \\
\hline$\geq 56$ & 23 & 8 (E2, E6, E55, E80, E84, E87, E96, E140) \\
\hline Total & & 56 \\
\hline
\end{tabular}

E (ESR), Embryo Serial Section Registry of Seoul National University Hospital (SNUH); R (RCM), Registry of Congenital Malformation at the SNUH.

Table 2. Human fetuses used in this study

\begin{tabular}{|c|c|}
\hline $\begin{array}{l}\text { Gestational } \\
\text { age (wk) }\end{array}$ & No. of ESR, RCM, or CHA \\
\hline 10 & 4 (E11, E41, E81, E156) \\
\hline 11 & 3 (E111, R1057, R1532) \\
\hline 12 & $1(\mathrm{E} 123)$ \\
\hline $13-14$ & 3 (E50, E98, R1529) \\
\hline $15-16$ & 3 (R308, R1526, R1533) \\
\hline $17-18$ & 1 (R1524) \\
\hline 19-20 & 7 (R291, R293, R379, R398, R414, R567, A89-2) \\
\hline $21-22$ & 6 (R299, R326, R422, R738, R1419, A89-54) \\
\hline $23-24$ & $\begin{array}{l}12 \text { (R247, R248, R263, R285, R301, R318, R352, R353, } \\
\text { R437, R727, R733, R736) }\end{array}$ \\
\hline $25-26$ & 8 (R281, R284, R287, R300, R399, R403, R737, R1483) \\
\hline $27-28$ & $\begin{array}{l}11 \text { (R249, R250, R253, R267, R270, R375, R406, R438, } \\
\text { R506, R739, R1535) }\end{array}$ \\
\hline $29-30$ & $\begin{array}{l}9 \text { (R259, R309, R316, R349, R388, R390, R409, R429, } \\
\text { R507) }\end{array}$ \\
\hline $31-32$ & $\begin{array}{l}9 \text { (R252, R297, R303, R311, R358, R362, R382, R424, } \\
\text { R451) }\end{array}$ \\
\hline $33-34$ & 6 (R266, R289, R366, R407, R416, A80-34) \\
\hline $35-36$ & $4(\mathrm{R} 355, \mathrm{R} 402, \mathrm{R} 1480, \mathrm{~A} 80-20)$ \\
\hline $37-38$ & $\begin{array}{l}9 \text { (R298, R347, R354, R361, R364, R365, R389, R451, } \\
\text { A88-76) }\end{array}$ \\
\hline $39-40$ & 6 (R294, R295, R319, R356, R370, R408) \\
\hline$\geq 41$ & 4 (R423, A87-87, A88-72, A87-94) \\
\hline Total & 106 \\
\hline
\end{tabular}

E (ESR), Embryonal Serial Section Registry of Seoul National University Hospital (SNUH); R (RCM), Registry of Congenital Malformation at the SNUH; A (CHA), Children's Hospital for Autopsy at the SNUH.

analyzed tongue positions relative to the facial and cranial base structures. In sagittal sections of microscopic specimens, four developmental planes were traced (1) the ACB plane (from the center of the hypophyseal fossa to the embryonic soft tissue nasion), (2) the PCB plane (the slope of the PCB starting from the center of the hypophyseal fossa), (3) the primary maxillary plane (from the center of the hypophyseal fossa to the most inferior 
and anterior point of the premaxilla), and (4) the tongue axis (from the foramen cecum of the tongue to the tongue apex). On adult cephalometric $\mathrm{X}$-ray films, these respectively constitute the ACB plane (nasion-sella turcica), the PCB plane (sella turcica-articulare), the maxillary plane (sella turcica to point A), and the tongue axis (foramen cecum of the tongue to the tongue apex). In order to analyze the role played by the tongue in embryogenesis, we measured the angles made by these planes in sagittal sections of histologic specimens and on cephalometric X-ray films.

During embryogenesis, tongue growth and development were prominent between FA 28 and 56 days (Streeter's stages, 13 and 23), and thus, we used a grading system for morphogenesis of the tongue described in the literature, ${ }^{6,7,30-33}$ which classifies tongue development (TD) into eight stages (Table 3).

In TD stage 1 (score 1), tongue primordium aggregates on the medial mandible and bulges on the posterior side of the stomodeum while compressing Rathke's pouch. During this stage, tongue primordium is visualized as a mesial swelling, which forms the tuberculum impar. However, at this stage it is not well demarcated from the first branchial arch.

In TD stage 2 (score 2), the hypoglossal nerve (XII) is distributed into the tongue primordium. As a result, the hypoglossal nerve fibers are observed as thick bundles. The tongue apex is proliferative and bulges to the lateral side to form the central lingual septum. Subsequently, the tongue primordium produces a pair of lateral swellings. The tongue gradually compresses the nasopharynx and grows both superiorly and anteriorly to fill the superior and posterior stomodeal spaces underneath the PCB. Simultaneously, the posterior $1 / 3$ of the tongue and the copula bulge eventually influence formation of the posterior curvature of the PCB. As a result, the apex of the tongue is located at the anterior region of the PCB, i.e., around Rathke's pouch.

In TD stage 3 (score 3), the tongue grows continuously and its apex is located vertical to the posterior region of the nasal cavity. At this time, the dorsal surface of the tongue fills the nasopharynx. While the olfactory placode continues to grow actively and communicates with the posterior nasal cavity, the apex of the tongue is located within the posterior nasal cavity and subsequently attaches to the orifice of the olfactory placode. Meanwhile, extrinsic tongue muscle is rapidly rearranged by myoblast differentiation to create the hyoglossus, genioglossus, and styloglossus muscle groups. In addition, proliferation of the hypoglossal nerve advanced to the distribution of the lingual nerve to the lateral sides of the tongue.

In TD stage 4 (score 4), the tongue changes from a vertical to a horizontal position. Arranged in an orderly concentric manner, the genioglossus muscle is attached to Meckel's cartilage of the mandibular arch and then closely connects with the tongue. Extrinsic tongue muscle fibers of the genioglossus and hyoglossus muscles become thickened but show no cross-striation. The apex remains located at the posterior side of the nasal cavity, and the palatal shelf rapidly proliferates and progresses to the lateral side of the tongue.

In TD stage 5 (score 5), the tongue is positioned horizontally within the oral cavity. The mandibular arch grows in the anterior and inferior directions, and the genioglossus muscle attached to Meckel's cartilage pulls the tongue both anteriorly and inferiorly in order to position the tongue horizontally in the oral cavity. At this time, most palatal shelves proliferate rapidly with mesenchymal swelling to cover the dorsal surface of the tongue, which results in closure of the secondary palate. The extrinsic

Table 3. Score points according to the TD developmental stages

\begin{tabular}{|c|c|}
\hline TD stage & Characteristic findings \\
\hline Score 1 (TD stage 1) & Mesial swelling of tongue primordium: tuberculum impar formation, concentration of mesenchymal cells. \\
\hline Score 2 (TD stage 2) & $\begin{array}{l}\text { Lateral swelling of tongue primordium and vertically occupation of the entire stomodeal space. It was elongated into the } \\
\text { nasopharyngeal area, which was innervated by the hypoglossal nerve. The copula was formed from a second mesial swelling } \\
\text { at the posterior tongue. }\end{array}$ \\
\hline Score 3 (TD stage 3) & $\begin{array}{l}\text { Vertical positioning of tongue: involving occupation of the posterior nasopharyngeal space, development of the hypoglossal nerve } \\
\text { and tongue muscle, and rapid growth of the olfactory placode to form the naso-pharyngeal passage. }\end{array}$ \\
\hline Score 5 (TD stage 5) & $\begin{array}{l}\text { Horizontal positioning of the tongue: as the mandible grew inferior-anteriorly the tongue was pulled by thick genioglossus muscle } \\
\text { inferior-anteriorly. The vertical surface of the tongue was parallel to the palatal shelf. }\end{array}$ \\
\hline Score 6 (TD stage 6) & $\begin{array}{l}\text { Protrusion of the tongue on the horizontal plane: indentation by both alveolar ridges at the anterior tongue; cross-striation began } \\
\text { to appear in extrinsic tongue muscle. }\end{array}$ \\
\hline Score 7 (TD stage 7) & $\begin{array}{l}\text { Differentiation of tongue muscle: intrinsic tongue muscle developed well and extrinsic tongue muscles were in the state of } \\
\text { equilibrium with each other. However, many myoblasts were observed between mature striated muscles. }\end{array}$ \\
\hline
\end{tabular}

TD, tongue development. 
tongue muscles become prominent; that is, the genioglossus muscle develops extensively in the anterior and posterior regions in a concentric manner, and the hyoglossus and styloglossus muscles thicken.

In TD stage 6 (score 6), the tongue protrudes to the anterior region of the oral cavity and attaches to the palatal side of the premaxilla while vertical to the palatal plane within the oral cavity. During forward and backward movement of the tongue, the anterior tongue is indented by intimate attachment to the upper and lower lips. In addition, primitive maxillary and mandibular swellings become dominant in the space between the tongue and the upper and lower lips.

In TD stage 7 (score 7), the cells forming tongue muscles are actively differentiated into intrinsic and extrinsic muscles. In particular, the alignments of extrinsic tongue muscles such as the hyoglossus, genioglossus, and geniohyoid muscles become distinct. The pulling of these muscles anteriorly and posteriorly proportionally positions the tongue within the oral cavity. Furthermore, tongue muscles begin to show cross-striation.

In TD stage 8 (score 8), tongue muscles undergo maturation. Muscle fibers become enlarged with conspicuous cross-striation, and the muscles are closely arranged. Due to forward tongue movement, the anterior tongue shows an indentation formed by the upper and lower lips and maxillary and mandibular arches.

\section{RESULTS}

\section{Evaluation of prenatal human TD stages}

TD was observed with serial sections of human embryos and in representative sections of fetal tongues and estimated by the 8 TD stages ( 8 scores) described above and in Tables 3 and 4 .

\section{TD stage 1: Mesial swelling of tongue primordium in the stomodeal cavity}

From Streeter's stage 13 (FA, 28 to 30 days), primitive branchial arches were observed around the cervix and became prominent through Streeter's stage 14-15 (FA, 31 to 36 days). These branchial arches were covered with a thin layer of epithelial cells with a mesenchymal cell core (Fig. 1A, B). In Streeter's stage 15 (FA, 33 to 36 days) the first branchial arch swelled dominantly and became the largest and was demarcated from surrounding tissues. The first branchial arch formed the lower face and gradually bulged. Blood vessels actively proliferated within the first branchial arch, and subsequently, the second, third, fourth, and fifth branchial arches gradually and sequentially bulged. In addition, blood vessel proliferation was observed within these
Table 4. Developmental scores of human tongue during prenatal period

\begin{tabular}{|c|c|c|}
\hline Prenatal period & No. of cases & Score average \\
\hline \multicolumn{3}{|l|}{ Streeter's stage } \\
\hline 13 & 5 & 1.0 \\
\hline 14 & 4 & 1.0 \\
\hline 15 & 8 & 1.0 \\
\hline 16 & 4 & 1.8 \\
\hline 17 & 9 & 2.0 \\
\hline 18 & 3 & 2.7 \\
\hline 19 & 2 & 3.0 \\
\hline 20 & 6 & 3.0 \\
\hline 21 & 3 & 3.7 \\
\hline 22 & 4 & 4.0 \\
\hline 23 & 8 & 4.8 \\
\hline Subtotal & 56 & \\
\hline \multicolumn{3}{|l|}{ Weeks (GA) } \\
\hline 10 & 4 & 5.3 \\
\hline 11 & 3 & 6.3 \\
\hline \multicolumn{3}{|l|}{ Months (GA) } \\
\hline 3 & 3 & 6.7 \\
\hline 4 & 5 & 7.0 \\
\hline 5 & 13 & 7.2 \\
\hline 6 & 20 & 7.7 \\
\hline 7 & 20 & 7.9 \\
\hline 8 & 15 & 8.0 \\
\hline 9 & 13 & 8.0 \\
\hline 10 & 10 & 8.0 \\
\hline Total & 106 & \\
\hline
\end{tabular}

GA, gestational age.

${ }^{\text {TT }}$ The developmental score of human tongue is based on the tongue development stages.

arches. Finally, the cervix was partly outlined.

The tongue primordium was observed on the medial side of the first and second branchial arches, which were arch-shaped from Streeter's stage 13, and primitive mesenchymal cells of the primordium migrated from the inferior to the superior. At this time, the first mesial swelling of the tongue, the tuberculum impar, was seen in the oral cavity. Posteriorly to the mesial swelling, infiltration and proliferation of the thyroid primordium were also noted (Fig. 2A). In Streeter's stage 14 (FA, 31 to 32 days), the second and third mesial tongue swellings were clearly seen posterior to the first mesial swelling; these were destined to differentiate into copula (or hypobranchial eminence) and epiglottal swelling, respectively (Fig. 1C).

From Streeter's stage 15 (FA, 33 to 36 days) mesenchymal cells of branchial arches actively migrated distally to differentiate in a uniform direction. Migrating from the occipital myotome to the oral cavity, most of the distally extended mesenchyme of the tongue primordium differentiated into extrinsic tongue muscles. At this time, the mandibular primordium was 
located more posteriorly than the cranial region. Accordingly, mesial swelling of the tongue protruded superiorly from the posterior oral cavity and compressed the inferior portion of Rathke's pouch. The tongue continuously proliferated towards the spheno-occipital synchondrosis, which corresponded to prechordal mesenchyme in the superior to posterior portions of the oral stomodeum (Figs. 1A-D, 2A, 2B). TD stage 1 corresponds to Streeter's stages 13-15 (FA, 28 to 36 days).
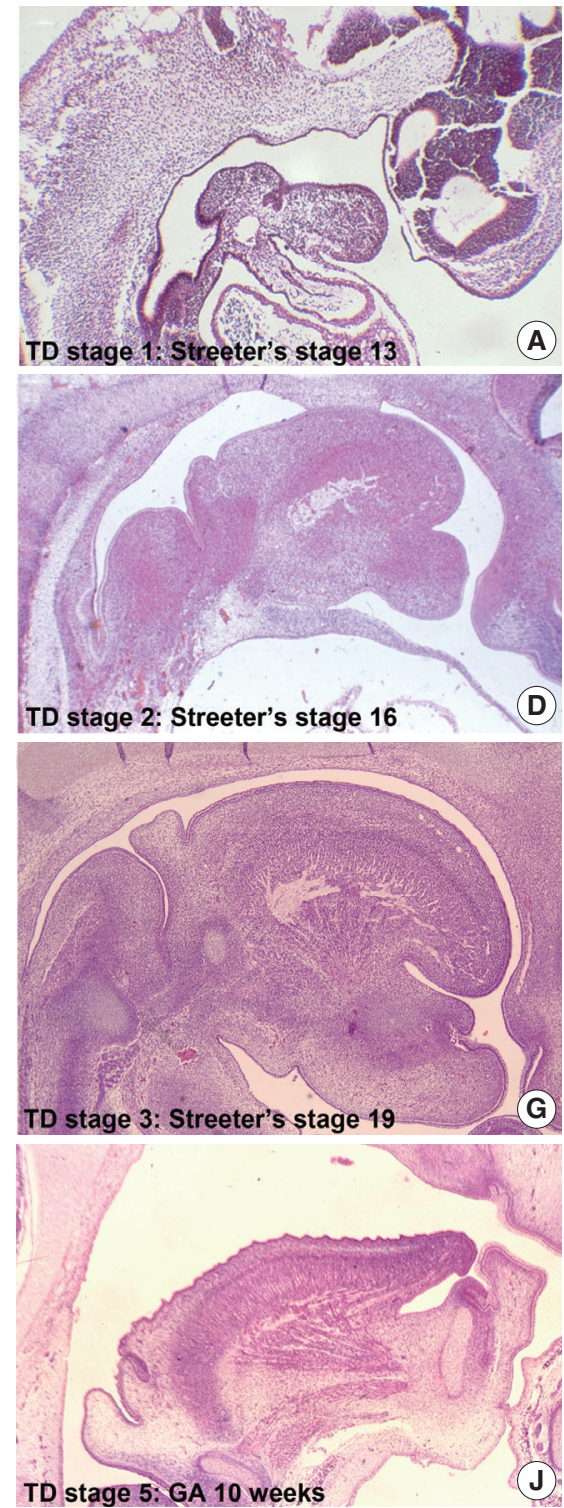

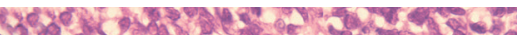
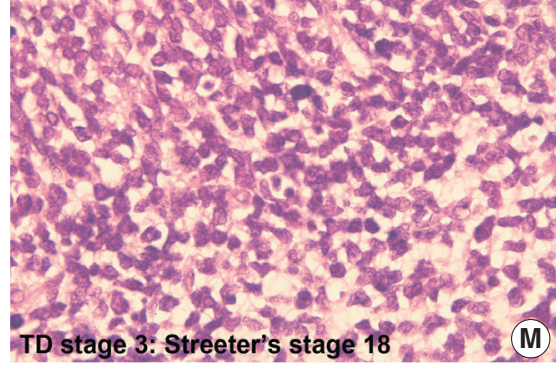

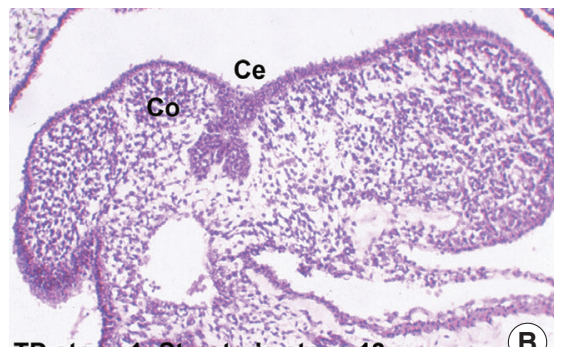

TD stage 1/ Streeter's stage 13

\section{(B)}
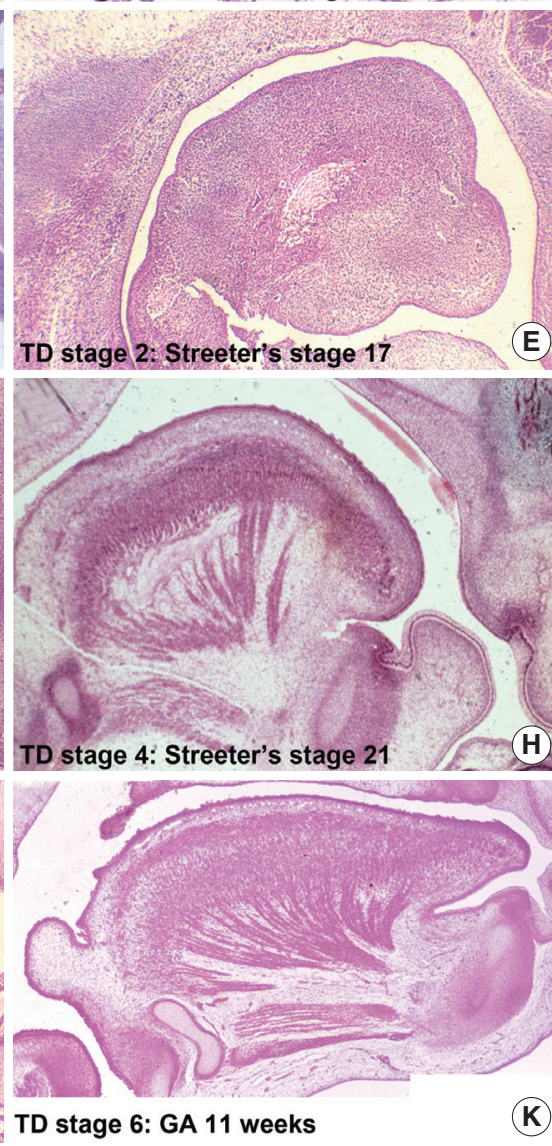

K
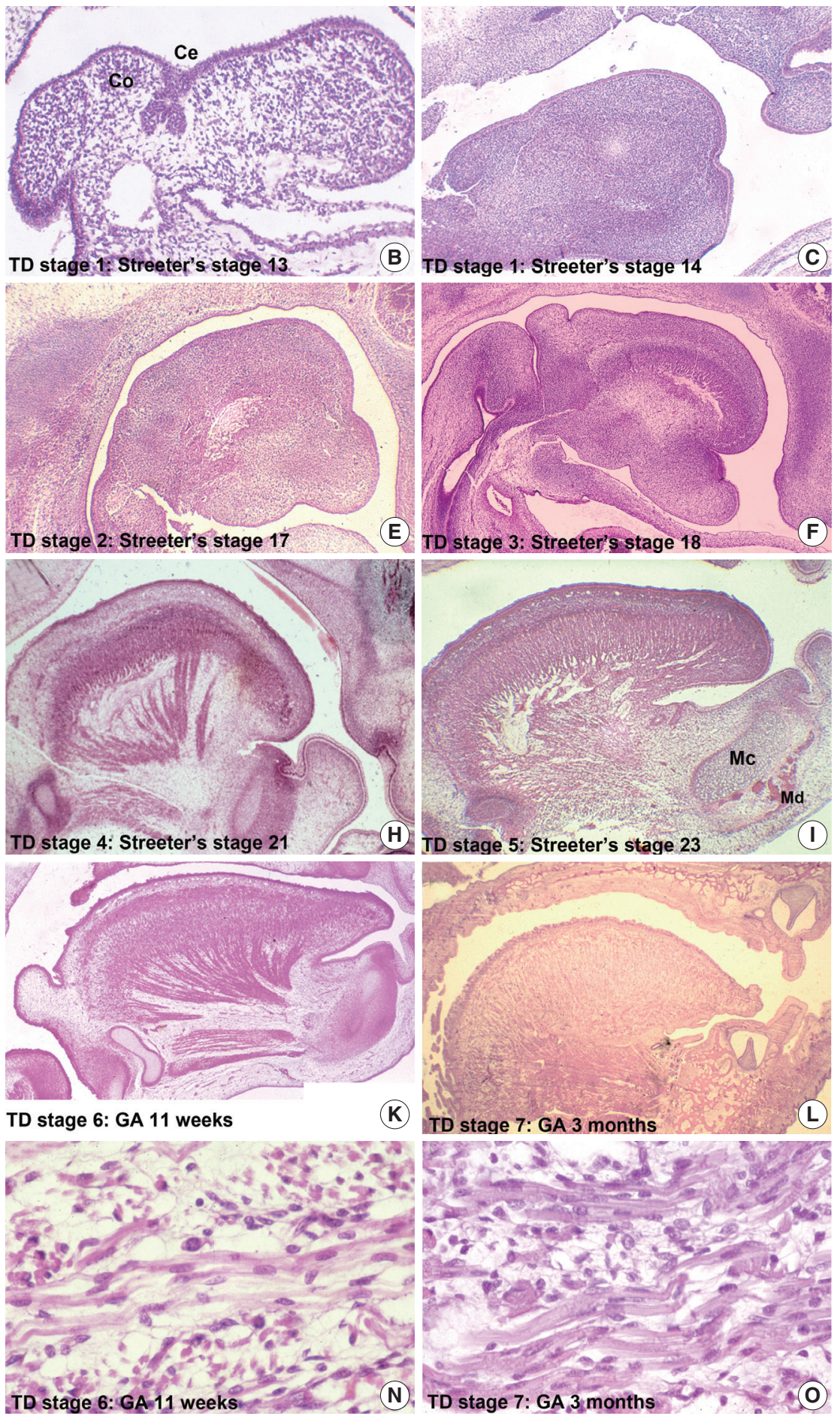

Fig. 1. Organogenesis of a fetal tongue. Photographs of mid-sagittal sections of an embryonic human tongue. (A, B) Tongue development (TD) stage 1. Co, copula; Ce, foramen cecum. (C) TD stage 1. (D, E) TD stage 2. (F, G) TD stage 3. (H) TD stage 4. (I, J) TD stage 5. MC, Meckerl's cartilage; Md, mandible. (K) TD stage 6. (L) TD stage 7. Microscopic features of tongue muscle at TD stage $3(\mathrm{M})$, TD stage 6 (N), and TD stage 7 (O). 
TD stage 2: Lateral swelling of tongue primordium and its vertical occupation of the whole stomodeal cavity

At Streeter's stage 16 (FA, 37 to 40 days), the mandibular primordium of the first branchial arch differentiated into Meck- el's cartilage, and Reichert's cartilage was formed within the second branchial arch. A mesial swelling was differentiated into a pair of lateral swellings both anteriorly and superiorly on bilateral sides (Fig. 2B). Continuously protruding both anteriorly
(A)

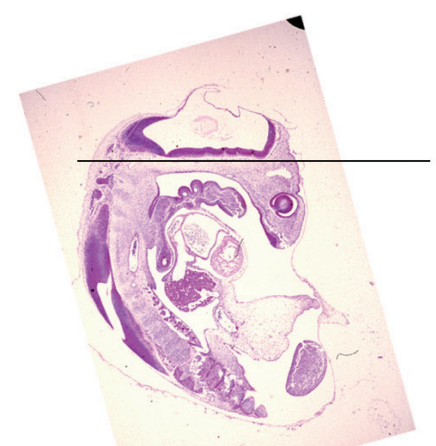

TD stage 1: Streeter's stage 13

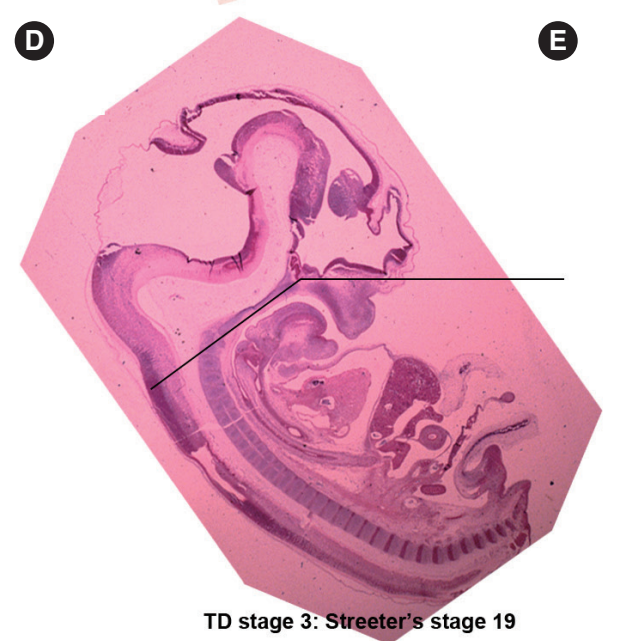

G

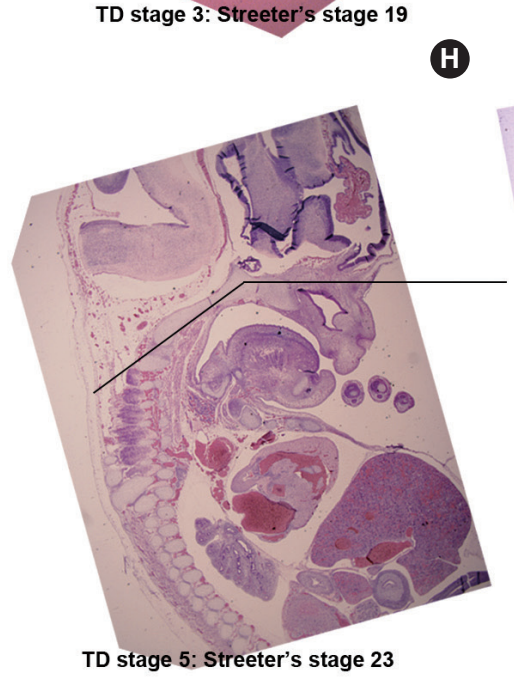

B

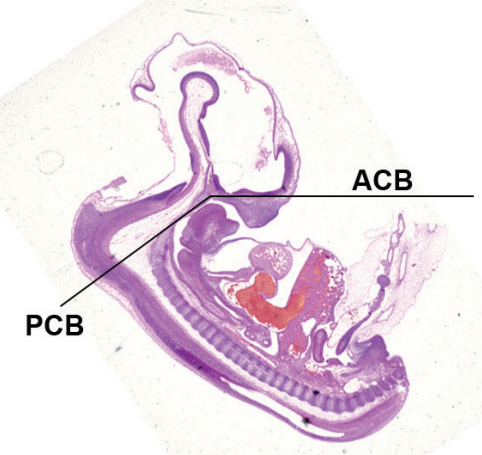

TD stage 2 : Streeter's stage 16

\section{C}
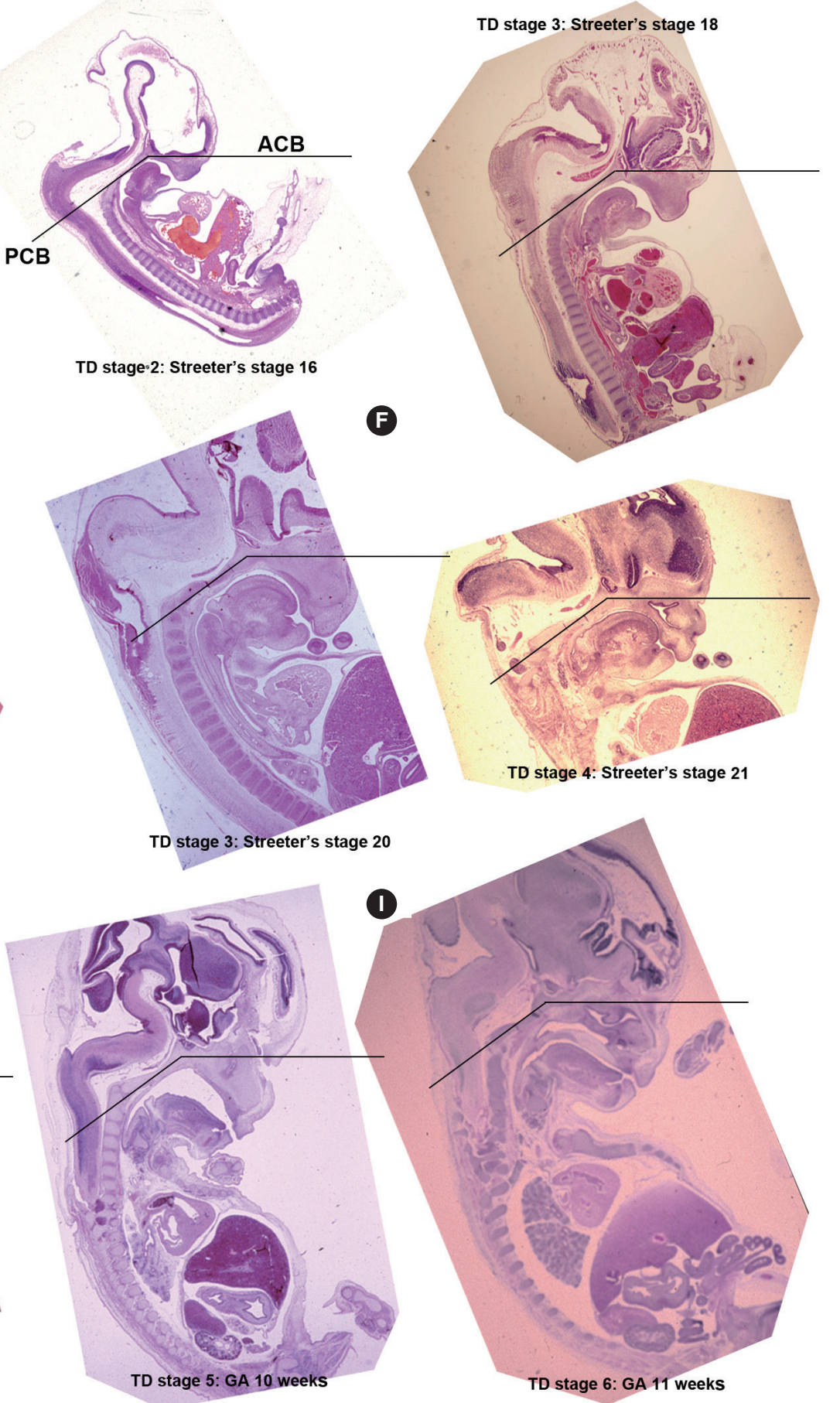

TD stage 4: Streeter's stage 21

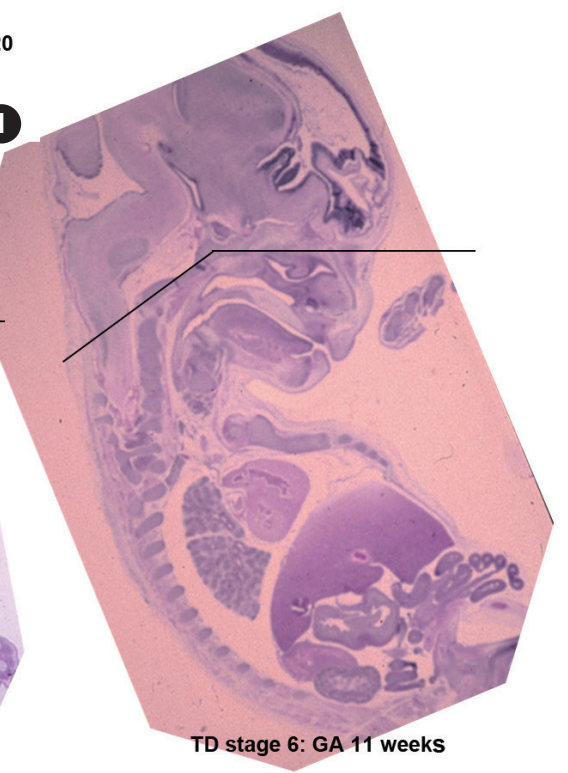

Fig. 2. Sequential tongue development (TD) stages during the early embryonic period aligned with anterior cranial base (ACB) and posterior cranial base (PCB) lines. (A) TD stage 1. (B) TD stage 2. (C-E) TD stage 3. (F) TD stage 4. (G, H) TD stage 5. (I) TD stage 6. 
and superiorly and then indistinguishably from mesial swelling, the lateral swelling was separated bilaterally by the lingual septum (Fig. 1D). In Streeter's stage 17 (FA, 41 to 43 days), copula swelling (hypobranchial eminence) became distinct. This lateral swelling filled the posterior curvature of the pharynx and then proliferated both anteriorly and superiorly (Fig. 1E). Subsequently, the primitive stomodeal cavity was wholly occupied by the proliferating and protruding tongue (Figs. 1E, 1F, 2C, 2D). The TD stage 2 corresponds with Streeter's stages 16-17 (FA, 37 to 43 days).

\section{TD stage 3: Vertical position of the tongue and its occupation of na- sopharyngeal space}

From Streeter's stage 18 (FA, 44 to 46 days), the tongue mesenchyme proliferated and was filled with undifferentiated myoblasts (Fig. 1M). The hyoglossus muscle was arranged between the tongue and hyoid cartilage, the genioglossus muscle was arranged between the tongue center and Meckel's cartilage, and the styloglossus muscle was between the tongue center and the temporal portion of the cranial base. At this time, the mandible was located more posteriorly and was smaller than the maxilla. Accordingly, the tongue protruded vertically and expanded the posterior stomodeal space for nasopharyngeal development (Figs. 1F, 2C). In Streeter's stage 19 (FA, 47 to 48 days), as the mandible grew anteriorly and inferiorly, the tongue was pulled slightly downward and forward by the anterior portion of the genioglossus muscle (Fig. 2D). The nasal plate actively proliferated and then communicated with the posterior nasal cavity. The apex of the tongue moved to communicate between the nasal plate and the posterior nasal cavity and began to curve anteriorly, although the tongue body was still located at the proximal site (Fig. 1G). However, in Streeter's stage 20 (FA, 49 to 51 days), the tongue was widely distended superiorly, anteriorly, and inferiorly (Fig. 2E). TD stage 3 corresponds to Streeter's stages 18-20 (FA, 44 to 51 days).

\section{TD stage 4: Transitional stage from a vertical to horizontal tongue position}

In Streeter's stage 21 (FA, 52 to 53 days) the tongue protruded and elongated within the oral cavity (Fig. 2F). The mandible was still located more posteriorly than the maxilla. While Meckel's cartilage enlarged, mandible growth was initiated on the lateral side of Meckel's cartilage and then progressed anteriorly and inferiorly. Fibers of the genioglossus muscle became distinct and tracked the tongue to attach to the perichondral mesenchymal tissue of Meckel's cartilage. This process lowered the tongue both anteriorly and inferiorly as illustrated in Fig. 3. A huge empty space appeared for the nasopharyngeal structure in the posterior stomodeal cavity (Fig. $1 \mathrm{H}$ ). In Streeter's stage 22 (FA, 54 to 55 days), the extrinsic tongue muscles appeared much more mature, and the genioglossus muscle fibers previously attached to Meckel's cartilage migrated anteriorly to the posterior side of the mandible (Fig. 1N). Accordingly, the arrangement of the genioglossus muscle fibers attached to the tongue center became concentric and distinct. Moreover, the arrangement of hyoglossus muscle cells became distinct and hyoglossus muscle fibers actively proliferated. At this time, the genioglossus muscle pulls the tongue both anteriorly and inferiorly. As a result, the tongue was rapidly lowered in the same direction and located in transition between the vertical and horizontal positions (Figs. 1I, 2G). TD stage 4 corresponds to Streeter's stages 21-22 (FA, 52 to 55 days).

\section{TD stage 5: Horizontal positioning of the tongue in the oral cavity}

In Streeter's stage 23 (FA, 56 days), the tongue was lowered both anteriorly and inferiorly and located on the horizontal

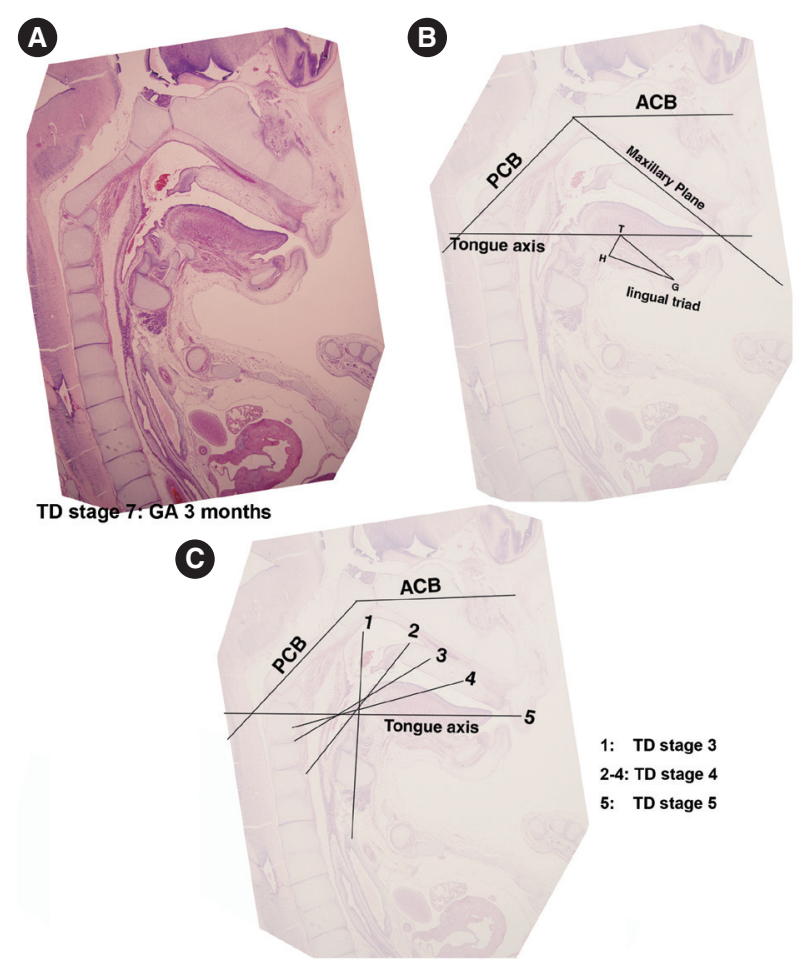

Fig. 3. Measurements of the dispositions of tongue developmental planes, tongue development (TD) stage 7. (A, B) Planes of the anterior cranial base $(A C B)$, the posterior cranial base $(P C B)$, the maxillary plane, and tongue axis. (C) The tongue axis gradually rotated in a clock-wise manner, vertical to the horizontal $(1 \rightarrow 5)$ during the prenatal period. GA, gestational age. 
plane. However, the mandible was still shifted slightly posterior to the maxilla. Accordingly, the tongue apex was attached to incisive papilla of the premaxilla. In addition, the lower lip was seen within the oral cavity. The palatal shelf rapidly proliferated and gradually closed as the nasal septum grew downward to result in nasal cavity formation (Fig. 2G). Tongue muscle cells were arranged in a relatively harmonious manner; the genioglossus, hyoglossus, styloglossus, and geniohyoid muscles were clearly distinguishable. Nevertheless, no cross-striation was observed in these muscles at this stage. In particular, genioglossus muscle growth became prominent both anteriorly and posteriorly, and the arrangement of the posterior genioglossus muscle fibers, which track the tongue both anteriorly and inferiorly, became notable in the center of the tongue (Fig. 1I). Subsequently, a large space for the nasopharynx was generated (Fig. $2 \mathrm{G})$. At the same time, the spheno-occipital synchondrosis became active and enlarged, producing an anteroposterior cranial base angle, which eventually formed the roof of the nasopharynx.

At gestational age (GA) 10 weeks, growth of the nasal capsule gradually progressed. Accordingly, the nasal septum was inferiorly enlarged. The anterior part of the nasal septum fused with the premaxilla to form the primary palate. Meanwhile, the posterior part of the nasal septum grew progressively. The lowered palatal shelf migrated from the posterior part to the dorsal side of tongue and was positioned horizontally (Figs. 1J, 2H). Subsequently, the palatal shelf rapidly enlarged and formed the secondary palate by fusing with the nasal septum, which was inferiorly growing from the prechordal mesoderm. TD stage 5 corresponds to Streeter's stage 23 (FA, 56 days; GA, 10 weeks).

\section{TD stage 6: Protrusion of the tongue in the horizontal plane}

At approximately GA 11 weeks, mandibular growth was more advanced than maxillary growth, resulting in the two being at almost the same level. As the tongue was located in the horizontal plane, its forward movement gradually progressed (Fig. 2I). The tongue apex was attached to incisive papilla of the premaxilla. Growth of the mandible became prominent and the mandible body was enlarged on the lateral side of Meckel's cartilage, from which it gradually separated. The growth of mandibular bony trabeculae progressed laterally (Fig. 1K). Insertions of digastric and mylohyoid muscles were completely changed from Meckel's cartilage to the mandible. The lower lip was located posterior to the upper lip and closely associated with the tongue apex, causing an indentation in the anterior tongue. On the other hand, the nasal septum continued to proliferate inferiorly. Meanwhile, the nasal septum was involved in the formation of the vomer, a plate-like structure posterior to its anterior part, and subsequently associated with the formation of the hard palate by fusing with the palatal shelf. Moreover, the posterior extended tissue of the palatal shelf formed the soft palate as it fused with the nasal septum without any communications. Finally, the soft palate covered the anteriorly located tongue root. TD stage 6 corresponds to GA 11 weeks.

\section{TD stage 7: Differentiation of tongue muscle cells}

At around GA 3 months, when facial muscles are not welldeveloped, the genioglossus and hyoglossus muscles were found to exhibit bundle-like arrangements of muscle fibers with conspicuous cross-striation (Fig. 1O). In the tongue, the hyoglossus, genioglossus, styloglossus, and glossopalatinus muscles are classified as extrinsic muscles; at the hyoid bone, mandible, and cranial base, they are classified as the geniohyoid, mylohyoid, and stylohyoid muscles, respectively (Fig. 1L). At approximately GA 4 months, the tongue muscles were well developed and subsequently enlarged. Intrinsic tongue muscles were not well developed until approximately GA 5 months. TD stage 7 corresponds to GA 3-5 months.

\section{TD stage 8: Maturation of tongue muscle}

After GA 6 months, tongue muscle growth became prominent, muscle fibers were enlarged, and cross-striation was clearly observed. The fascicles of the extrinsic tongue muscles were tightly connected, and the development of intrinsic muscles became prominent. Thus, they were distinguishable from extrinsic muscles. At approximately GA 8 months, tongue muscle maturation was almost complete. At this time, cross-striation was clearly observed and muscular fascicles became thicker with few undifferentiated myoblasts (Fig. 1O). TD stage 8 corresponds to the period from GA 6 months.

\section{Formation of the lingual frenum}

In Streeter's stage 19, the tongue was superiorly directed to the nasal cavity, and in Streeter's stage 23, it was anteriorly tracked by mandible growth and the genioglossus muscle. At this time, mucosa located anterior to the genioglossus muscle was much extended, and a thin membranous structure was formed on the ventral surface (termed the lingual frenum) (Fig. 4A, B). Until GA 10 weeks, the lingual frenum was covered with thin oral mucosal epithelium, and it contained only a small amount of connective tissue and subsequently fused to the lingual septum (Fig. 4C). The tongue apex migrated both anteriorly and inferiorly after GA 11 weeks. At approximately GA 12 weeks, mus- 
cle fibers of the external tongue muscles were more matured, and at this stage, the tongue performed forward and backward movements in the horizontal plane. The membranous lingual frenum became the anterior margin that supported forward and backward movements of the tongue (Fig. 4).
Relations between the cranial base and facial structures

\section{ACB plane to $P C B$ plane angle (Saddle angle)}

The angle between the ACB and PCB planes constitutes a basic craniofacial structure and was almost flat $\left(180^{\circ}\right)$ in Street-

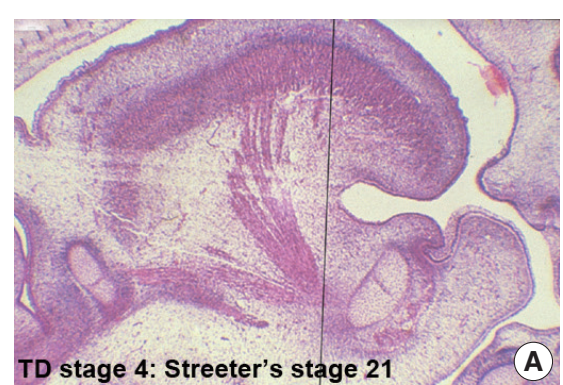

Fig. 4. Formation of the lingual frenum in human embryos. (A) Mid-sagittal section of the human tongue at tongue development (TD) stage 4, the vertical line indicates the frontal section planes for panel B. (B) Frontal section of human embryo at TD stage 4, indicating the membranous covering of the lingual frenum (arrows). (C) Frontal section of a human embryo at TD stage 5, showing the close connection between the lingual frenum and lingual septum (LS). GA, gestational age.
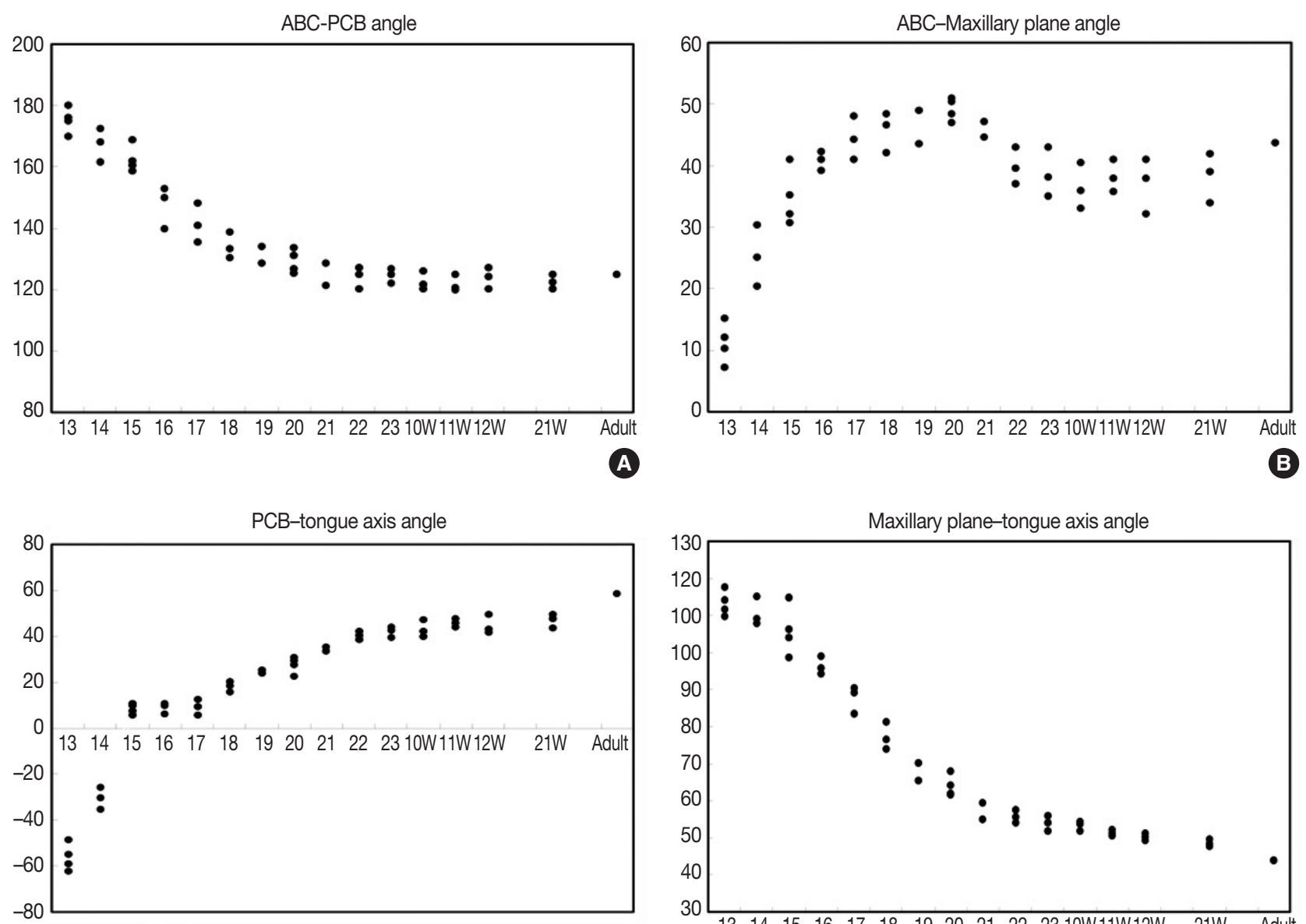

C

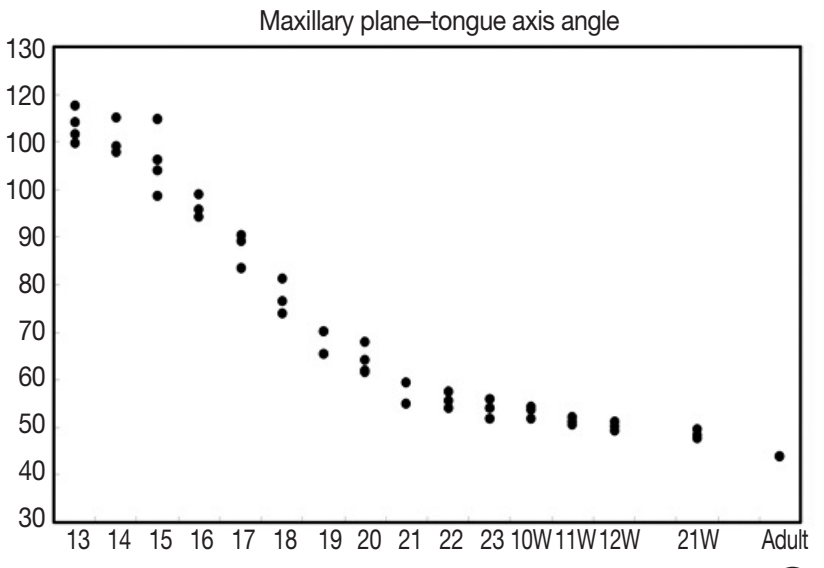

Fig. 5. (A-D) Incremental change graphs of the four developmental angles (Table 5); anterior cranial base (ACB) to posterior cranial base (PCB) angle, ACB-maxillary plane angle, PCB-tongue axis angle, and maxillary plane-tongue axis angle. 
er's stage 13 before the tongue pressed the cranial base (Fig. $2 \mathrm{~A}$ ). The tongue migrated from the occipital myotome to the stomodeal cavity and pressed the hypophyseal fossa area to form this angle, which reduced in accordance with FA. In Streeter's stage 17 , this angle was about $160^{\circ}$, and in Streeter's stage 19 it reduced from $120^{\circ}$ to $130^{\circ}$ to reach $124^{\circ}$ to $126^{\circ}$ in Streeter's stage 23 . We observed that this value was maintained at FA 21 weeks in histological sections and was similar in adult cephalograms. The mean saddle angle obtained by the cephalogram tracing of 30 normal adults was $116^{\circ}$ to $131^{\circ}$ with a mean of $124.8^{\circ}$, which is comparable to other reports that the saddle angle of normal adult men and women are $124^{\circ} \pm 5^{\circ}$ and $126^{\circ}$ $\pm 5^{\circ}$, respectively. Therefore, we presume that this saddle angle almost matures during the early prenatal period (at FA 8 weeks) due to compression by the emerging tongue (Fig. 5A).

\section{ACB plane to maxillary plane angle}

The ACB to maxillary plane angle represents facial clockwise growth. It was almost rudimentary at FA 4-5 weeks, but as the premaxilla grew downward from late during the fifth FA week, the ACB to maxillary plane angle increased to $32^{\circ}$ to $52^{\circ}$. This angulation was conspicuously observed in the mid-sagittal sections of embryos and early fetuses until GA 12 weeks. However, in the cephalograms of 30 normal adults, the ACB plane to maxillary plane angle averaged $40.5^{\circ}$ to $51.5^{\circ}$ (Fig. $5 \mathrm{~B}$ ).

\section{Tongue axis to $P C B$ angle}

The tongue axis to PCB angle is an important factor of facial counter-clockwise growth; it was almost negative when the tongue emerged at FA 4-5 weeks, but thereafter as the tongue protruded forward, this angle gradually became positive and increased to $47^{\circ}$ at FA 8 weeks. The tongue axis and PCB angle were relatively stable at $43^{\circ}$ at GA 12 weeks and remained almost constant until GA 21 weeks. In the cephalograms of 30 normal adults, the tongue axis to $\mathrm{PCB}$ plane angle ranged from $42^{\circ}$ to $72.5^{\circ}$ with an average value of $58.3^{\circ}$ (Fig. 5C).

\section{Tongue axis to maxillary plane angle}

Angulation between the tongue axis and the maxillary plane was observed from FA 5 weeks at $110^{\circ}$. As the tongue grew forward and downward and the tip of the tongue gradually fixed to the premaxilla, the tongue axis to maxillary plane angle became approximately $48^{\circ}$ from the FA 8 weeks and then remained constant until GA 21 weeks. In the cephalograms of 30 normal adults, the tongue axis to maxillary plane angle ranged from $32.5^{\circ}$ to $53.5^{\circ}$ with an average value of $43.7^{\circ}$ (Fig. 5D). Relations between the tongue and craniofacial structures are summarized in Table 5.

\section{DISCUSSION}

According to Moore (1982), ${ }^{14}$ the tongue primordium bulges late during the fourth FA week, and one mesial swelling and two lateral swellings proliferate while the tongue protrudes into the oral cavity. In the present study, we investigated the locations of TD with respect to overall maxillofacial structures, and

Table 5. Angulation changes during tongue development

\begin{tabular}{|c|c|c|c|c|}
\hline Age & ACB-PCB angle & ACB-maxillary plane angle & PCB-tongue axis angle & Maxillary plane-tongue axis angle \\
\hline \multicolumn{5}{|c|}{ Streeter's stage } \\
\hline 13 & $113.4 \pm 3.51$ & $-56.2 \pm 5.85$ & $175.3 \pm 4.11$ & $11.2 \pm 3.35$ \\
\hline 14 & $110.7 \pm 3.84$ & $-30.4 \pm 4.70$ & $167.4 \pm 5.34$ & $25.3 \pm 4.95$ \\
\hline 15 & $105.9 \pm 6.68$ & $8.5 \pm 2.20$ & $162.6 \pm 4.55$ & $34.8 \pm 4.59$ \\
\hline 16 & $96.3 \pm 2.51$ & $8.8 \pm 2.31$ & $147.6 \pm 6.69$ & $40.8 \pm 1.46$ \\
\hline 17 & $87.7 \pm 3.61$ & $9.2 \pm 3.41$ & $141.5 \pm 6.37$ & $44.4 \pm 3.50$ \\
\hline 19 & $67.8 \pm 3.94$ & $24.5 \pm 0.85$ & $131.3 \pm 3.96$ & $46.3 \pm 3.82$ \\
\hline 20 & $64.1 \pm 2.90$ & $27.6 \pm 3.59$ & $129.3 \pm 3.92$ & $49.3 \pm 1.85$ \\
\hline 21 & $57.2 \pm 2.97$ & $34.4 \pm 0.99$ & $125.1 \pm 5.09$ & $45.9 \pm 1.77$ \\
\hline 22 & $55.7 \pm 1.70$ & $40.4 \pm 1.80$ & $124.2 \pm 3.58$ & $39.9 \pm 3.01$ \\
\hline 23 & $53.9 \pm 2.06$ & $42.1 \pm 2.35$ & $124.6 \pm 2.36$ & $38.7 \pm 4.03$ \\
\hline \multicolumn{5}{|c|}{ Gestational age (wk) } \\
\hline 11 & $51.3 \pm 0.72$ & $45.9 \pm 1.80$ & $121.8 \pm 2.87$ & $38.2 \pm 2.66$ \\
\hline 12 & $50.2 \pm 0.90$ & $44.7 \pm-4.08$ & $123.9 \pm 3.46$ & $37.0 \pm 4.53$ \\
\hline 21 & $48.5 \pm 0.89$ & $47.0 \pm 2.98$ & $122.6 \pm 2.50$ & $38.3 \pm 4.10$ \\
\hline Adult & $43.8 \pm 5.00$ & $58.4 \pm 6.98$ & $124.8 \pm 6.98$ & $43.8 \pm 5.00$ \\
\hline
\end{tabular}

$\mathrm{ACB}$, anterior cranial base; PCB, posterior cranial base. 
we noted that the tongue and mandibular primordium were severely retruded as compared with the maxillary primordium. ${ }^{16,34,35}$ In particular, the origin of TD was located in the pharyngeal region and proliferation was rapid and resulted in compression of the inferior part of the PCB. This expanded the pharyngeal region and then affected the complete osteogenesis of the cranial base $e^{25,28}$ and secondary palate, ${ }^{34,36-38}$ in time for the formation of the spheno-occipital synchondrosis. Trenouth ${ }^{39,40}$ examined the fetal growth and development of the maxilla and mandible and found mandibular protrusion is obvious between GA 8 and 10 weeks, and that thereafter, the maxillary protrusion appears while the naso-maxillary segment enlarges. At the same time, the mandible grows anteriorly and inferiorly in harmony with maxillary growth. Diwert ${ }^{34}$ stressed that chondrocranium and Meckel's cartilage determine the locations of cranial base angulation and maxilla during the late fetal stage when early skeletal structures are formed. Our results showed cranial base angulation is closely associated with lingual swelling and vertical positioning of the tongue.

At approximately FA 8 weeks, mandibular growth, centered by Meckel's cartilage, pulls the tongue downward and forward, while growth of Meckel's cartilage is greatly increased. Our results showed that the tongue is transposed from the vertical to the horizontal axis from FA 7 weeks to the early eighth week (Streeter's stages, 20-23). At this time, the muscle cells forming the tongue muscles are premature. Between GA 10 and 12 weeks, protrusion of the tongue was noted while extrinsic tongue muscles were arranged in a harmonious manner. Furthermore, cells forming extrinsic muscles were progressively differentiated and cross-striation was observed, which suggests that forward and backward movement of tongue was initiated.

Humphrey ${ }^{35,41,42}$ proposed that opening and closing movements are caused by masseter and temporal muscle reflexes at approximately GA 12 weeks and suggested that prompt mandibular growth in the early embryonic stage is due to the intraoral appearance of the tongue and to the opening and closing movement. Our results show that TD progressed much faster than maxillofacial structural growth. To determine whether the developing tongue is associated with its adjacent branchial arches, we performed a histologic analysis to examine nerve distributions in serial sections. This analysis revealed that tongue muscles were closely related to masticatory and facial muscles and indicated that the earlier maturations of tongue muscles rather than facial musculature substantially affected the growth and development of maxillofacial structures. The present study demonstrates that the embryonic tongue originates from the occipital myotome, actively migrates into the stomodeal cavity through the retrohyoid space, and gradually swells beneath the primordial mesenchyme of the cranial base to form the angulation between the ACB and PCB. Furthermore, this angulation occurred rapidly, and the swollen tongue was directed perpendicularly to the angulation point. Subsequently, Rathke's pouch invaginated into the center of the sphenoid body, and thus, we propose that the swelling of embryonic tongue is related to angulation of ACB and PCB and to the formation of Rathke's pouch. In addition, we confirmed that the ACB-PCB angle matured at FA 8 weeks and then remained almost constant until full term and during postnatal life.

It has been reported that the developing tongue adjusts to functional changes during the postnatal stage. ${ }^{43}$ In patients with acromegaly, mandibular prognathism is rarely accompanied by a change in tongue size, but tongue size is greatly reduced in Beckwith-Wiedemann syndrome. ${ }^{44-46}$ However, in Down syndrome, muscular dystrophy is accompanied by tongue enlargement, ${ }^{47}$ which could compress the pharynx and lead to mandibular prognathism. ${ }^{48}$ Furthermore, it is well known that tongue enlargement occurs rapidly in Down syndrome patients who have a reduced number of teeth. ${ }^{47}$ Our results showed that TD affects the development of maxillofacial structures such as the maxilla, mandible, nasal cavity, pharynx, and larynx, either directly or indirectly. Because TD is one of the earliest events that progresses through the fetal stage, it can be inferred that the developmental rate of maxillofacial structures should be evaluated with reference to TD. As noted above, in the early embryonic stage, the tongue grows while it fills the pharynx, protrudes upward, and compresses the cranial base.

TD cannot be easily explained by its associations with other maxillofacial structures because its development involves its migration from the occipital myotome, which is unlike that of prechordal mesoderm or branchial arches of the cervix that form maxillofacial structures. ${ }^{6,7}$ In addition, the tongue is innervated by major cranial nerves. The lingual branch of the trigeminal nerve $(\mathrm{V})$ is distributed in mucosa at the tongue anterior, the chorda tympani branch of the facial nerve (VII) is distributed among taste buds in the anterior region, the glossopharyngeal nerve (IX) distributes to mucosa in the posterior region, branches of the vagus nerve $(\mathrm{X})$ are distributed in laryngeal constrictor muscle, and the hypoglossal nerve (XII) is distributed as a motor component in the skeletal muscles constituting tongue tissues. ${ }^{6,749-53}$ From early embryogenesis, the tongue is imbued with a wide variety of innervated cells, and thus, TD is influenced by the regulation of interactive functional reflexes, 
and this eventually affects the growth and development of maxillofacial structures.

In the present study, we examined lingual frenum formation during the embryonic period and defined the lingual frenum as a structure that supports anterior to posterior movement of the tongue. At the beginning of TD, the lingual frenum is a thin membranous covering of stomodeal mucosa that is gradually connected with the lingual septum centered by intrinsic tongue musculature. Previously, we supposed fibrous thickening of the lingual frenum in postnatal life limits tongue movement and results in ankyloglossia and designed a lingual myoplasty that differed from ordinary frenectomy to reduce the range of tongue movement. ${ }^{28,54,55}$ However, the present study demonstrates that the lingual frenum is produced as a result of positional changes of the embryonal tongue and that it functions as a reserved space for anterior extension of tongue movement.

In the present study, TD has been described as an 8-stage event involving mesial swelling of the tongue primordium, lateral swelling of the tongue within the oral fossa, vertical protrusion of the tongue, tongue transposition, horizontal location, anterior location, muscle differentiation, and tongue muscle maturation. Importantly, TD precedes that of other maxillofacial structures, and thus, changes in tongue position could be regarded as primary events of maxillofacial growth and development. In addition, because tongue muscles, masticatory muscles, and facial muscles move continually during fetal development, it is likely that the effects of the tongue on other maxillofacial structures continue even after birth. This suggests the tongue is an important organ that plays critical roles in the development of adjacent maxillofacial structures, such as the oral and nasal cavities, pharynx, and maxilla, and that abnormal TD might be related to congenital maxillofacial anomalies.

In summary, TD as observed during the present study indicates that the human tongue develops at an early embryonic age, that is, at approximately Streeter's stage 13 (FA, 28 to 30 days) as an anterior extension of the occipital myotome, which is earlier than that of any other orofacial structure, and that the tongue continues to develop and affects the formation of the cranial base, jaws, and nasopharyngeal structures. In our opinion, the morphogenetic impact of the tongue on craniofacial structures is substantial enough to affect the anatomy and essential functions of oro-facial structures. However, the extents of these changes and the mechanisms involved remain to be elucidated.

\section{Conflicts of Interest}

No potential conflict of interest relevant to this article was reported.

\section{Acknowledgments}

We express our sincere appreciation to the donors of human materials that made it possible to perform this study, which was initiated after obtaining legal approval from the Embryonal Serial Section Registry (ESR), the Registry of Congenital Malformation (RCM), and the Children's Hospital for Autopsy (CHA), Seoul National University Hospital (Seoul). We also express our gratitude to the late Professor Je G. Chi, who founded the ESR, RCM, and CHA. Professor Chi was a mentor and friend to all of the authors. We dedicate this study to his memory.

\section{REFERENCES}

1. Achtel LW, Cole LJ, Bailey JS. X-irradiation of defined areas of the heads of weanling rats: effect on body growth and incisor development. Radiat Res 1967; 31: 430-40.

2. Siebert JR. Prenatal growth of the median face. Am J Med Genet 1986; 25: 369-79.

3. Yamane A, Bringas P Jr, Mayo ML, et al. Transforming growth factor alpha up-regulates desmin expression during embryonic mouse tongue myogenesis. Dev Dyn 1998; 213: 71-81.

4. Uchiyama K, Ishikawa A, Hanaoka K. Expression of lbx1 involved in the hypaxial musculature formation of the mouse embryo. J Exp Zool 2000; 286: 270-9.

5. Nagata J, Yamane A. Progress of cell proliferation in striated muscle tissues during development of the mouse tongue. J Dent Res 2004; 83: 926-9.

6. Wozniak W. The peripheral part of the hypoglossal nerve in human embryos at stage 14 (32 days). Folia Morphol (Warsz) 1995; 54: 227-30.

7. O'Rahilly R, Muller F. The early development of the hypoglossal nerve and occipital somites in staged human embryos. Am J Anat 1984; 169: 237-57.

8. Vasyutina E, Stebler J, Brand-Saberi B, Schulz S, Raz E, Birchmeier C. CXCR4 and Gab1 cooperate to control the development of migrating muscle progenitor cells. Genes Dev 2005; 19: 2187-98.

9. Abu-Elteen KH, Abu-Alteen RM. The prevalence of Candida albicans populations in the mouths of complete denture wearers. New Microbiol 1998; 21: 41-8.

10. Aduss H, Pruzansky S. Postnatal craniofacial development in chil- 
dren with the oral-facial-digital syndrome. Arch Oral Biol 1964; 9: 193-203.

11. Achiron R, Ben Arie A, Gabbay U, Mashiach S, Rotstein Z, Lipitz S. Development of the fetal tongue between 14 and 26 weeks of gestation: in utero ultrasonographic measurements. Ultrasound Obstet Gynecol 1997; 9: 39-41.

12. Slavkin HC. Regulatory issues during early craniofacial development: a summary. Cleft Palate J 1990; 27: 101-9.

13. Dalrymple KR, Prigozy TI, Shuler CF. Embryonic, fetal, and neonatal tongue myoblasts exhibit molecular heterogeneity in vitro. Differentiation 2000; 66: 218-26.

14. Moore KL. The developing human: clinically oriented embryology. Philadelphia: W. B. Saunders, 1982.

15. Egerbacher M, Bock P. Lingual papillae. Am J Surg Pathol 1997; 21: 360.

16. Kim CH, Park HW, Kim K, Yoon JH. Early development of the nose in human embryos: a stereomicroscopic and histologic analysis. Laryngoscope 2004; 114: 1791-800.

17. Yamane A. Embryonic and postnatal development of masticatory and tongue muscles. Cell Tissue Res 2005; 322: 183-9.

18. Nie X. Apoptosis, proliferation and gene expression patterns in mouse developing tongue. Anat Embryol (Berl) 2005; 210: 125-32.

19. Streeter GL. Developmental horizons in human embryos: description of age groups XV, XVI, XVII, and XVIII, being the third issue of a survey of the Carnegie Collection. Carnegie Institution of Washington Publication 575. Contrib Embryol 1948; 32: 133-203.

20. Streeter GL, Heuser CH, Corner GW. Developmental horizons in human embryos: description of age groups XIX, XX, XXI, XXII, and XXIII, being the fifth issue of a survey of the Carnegie collection. Carnegie Institution of Washington Publication 592. Contrib Embryol 1951; 34: 165-96.

21. O'Rahilly R. Guide to the staging of human embryos. Anat Anz 1972; 130: 556-9.

22. Barlow LA, Northcutt RG. The role of innervation in the development of taste buds: insights from studies of amphibian embryos. Ann N Y Acad Sci 1998; 855: 58-69.

23. Swanson JJ, Kuehl-Kovarik MC, Elmquist JK, Sakaguchi DS, Jacobson CD. Development of the facial and hypoglossal motor nuclei in the neonatal Brazilian opossum brain. Brain Res Dev Brain Res 1999; 112: 159-72.

24. Lee SK, Kim YS, Lim CY, Chi JG. Prenatal growth pattern of the human maxilla. Acta Anat (Basel) 1992; 145: 1-10.

25. Lee SK, Kim YS, Jo YA, Seo JW, Chi JG. Prenatal development of cranial base in normal Korean fetuses. Anat Rec 1996; 246: 524-34.

26. Lee SK, Kim YS, Oh HS, Yang KH, Kim EC, Chi JG. Prenatal development of the human mandible. Anat Rec 2001; 263: 314-25.
27. Chi JG, Suh YL, Lee SK, et al. Atlas of human embryo and fetus: embryonic, anatomic, histologic and ultrasonographic observations. Seoul: Academya, 2001.

28. Lee SK, Lim CY, Chi JG. Development and growth of tongue in Korean fetuses. Korean J Pathol 1990; 24: 358-74.

29. Hong SJ. Study on the prenatal growth and development of tongue in Korean fetuses. Gangneung: Department of Oral Pathology, College of Dentistry Graduate School, Gangneung-Wonju National University, 2006.

30. Tamatsu Y, Gasser RF. Development of the sensory nerves to the dorsum of the tongue in staged human embryos. Clin Anat 2004; 17: 99-106.

31. Shuler CF, Dalrymple KR. Molecular regulation of tongue and craniofacial muscle differentiation. Crit Rev Oral Biol Med 2001; 12: 3-17.

32. Sato M, Sato T. Fine structure of developed human tongue muscle. Okajimas Folia Anat Jpn 1992; 69: 115-30.

33. Langdon H, Klueber K, Barnwell Y. The anatomy of M. genioglossus in the 15-week human fetus. Anat Embryol (Berl) 1978; 155: 107-13.

34. Diewert VM. A morphometric analysis of craniofacial growth and changes in spatial relations during secondary palatal development in human embryos and fetuses. Am J Anat 1983; 167: 495-522.

35. Humphrey T. Development of oral and facial motor mechanisms in human fetuses and their relation to craniofacial growth. J Dent Res 1971; 50: 1428-41.

36. Diewert VM. Differential changes in cartilage cell proliferation and cell density in the rat craniofacial complex during secondary palate development. Anat Rec 1980; 198: 219-28.

37. Diewert VM, Pratt RM. Selective inhibition of mandibular growth and induction of cleft palate by diazo-oxo-norleucine (DON) in the rat. Teratology 1979; 20: 37-51.

38. Greene RM, Pratt RM. Developmental aspects of secondary palate formation. J Embryol Exp Morphol 1976; 36: 225-45.

39. Trenouth MJ. Angular changes in cephalometric and centroid planes during foetal growth. Br J Orthod 1981; 8: 77-81.

40. Trenouth MJ. Changes in the jaw relationships during human foetal cranio-facial growth. Br J Orthod 1985; 12: 33-9.

41. Humphrey T. The relation between human fetal mouth opening reflexes and closure of the palate. Am J Anat 1969; 125: 317-44.

42. Humphrey T. Palatopharyngeal fusion in a human fetus and its relation to cleft palate formation. Ala J Med Sci 1970; 7: 398-426.

43. Niikuni N, Nakajima I, Akasaka M. The relationship between tongue-base position and craniofacial morphology in preschool children. J Clin Pediatr Dent 2004; 28: 131-4.

44. Friede H, Figueroa AA. The Beckwith-Wiedemann syndrome: a 
longitudinal study of the macroglossia and dentofacial complex. J Craniofac Genet Dev Biol Suppl 1985; 1: 179-87.

45. Laroche C, Testelin S, Devauchelle B. Cleft palate and BeckwithWiedemann syndrome. Cleft Palate Craniofac J 2005; 42: 212-7.

46. Wang J, Goodger NM, Pogrel MA. The role of tongue reduction. Oral Surg Oral Med Oral Pathol Oral Radiol Endod 2003; 95: 269-73.

47. Ardran GM, Harker P, Kemp FH. Tongue size in Down's syndrome. J Ment Defic Res 1972; 16: 160-6.

48. Skrinjaric T, Glavina D, Jukic J. Palatal and dental arch morphology in Down syndrome. Coll Antropol 2004; 28: 841-7.

49. Bradley RM, Mistretta CM, Nagai T. Demonstration of sensory innervation of rat tongue with anterogradely transported horseradish peroxidase. Brain Res 1986; 367: 364-7.

50. Matsushima TA, Satou M, Ueda K. Glossopharyngeal and tectal influences on tongue-muscle motoneurons in the Japanese toad. Brain Res 1986; 365: 198-203.

51. Mbiene JP, Mistretta CM. Initial innervation of embryonic rat tongue and developing taste papillae: nerves follow distinctive and spatially restricted pathways. Acta Anat (Basel) 1997; 160: 139-58.

52. Berger AJ, Bayliss DA, Viana F. Development of hypoglossal motoneurons. J Appl Physiol (1985) 1996; 81: 1039-48.

53. Vij S, Kanagasuntheram R. Development of the nerve supply to the human tongue. Acta Anat (Basel) 1972; 81: 466-77.

54. Lee SK, Kim YS, Lim CY. A pathological consideration of ankyloglossia and lingual myoplasty. J Korean Dent Assoc 1989; 27: 287-308.

55. Yoon JY, Lee I, Lee SS, et al. Cephalometric changes after lingual myoplasty for ankyloglossia associated malocclusions. Port Ortod 2005; 10: 1-17. 